\title{
POSSÍVEIS CONTRIBUIÇÕES DA ARGENTINA NA IMPLEMENTAÇÃO DA MEDIAÇÃO NO BRASIL
}

\author{
POSSIBLE CONTRIBUTIONS OF ARGENTINA IN THE \\ IMPLEMENTATION OF MEDIATION IN BRAZIL
}

\author{
Peter Panutto ${ }^{1}$ \\ Marília Morasca Monteleone ${ }^{2}$
}

Recebido em: $11 / 05 / 2017$

Aprovado em: 03/09/2017

\section{RESUMO}

Diante da previsão expressa no Novo Código de Processo Civil e também na Lei $\mathrm{n}^{\circ} 13.140 / 15$, a mediação ganhou extrema importância no Brasil como meio de solução de conflitos. Entretanto, tal realidade vem gerando questões de ordem prática, referentes à infraestrutura disponível para a realização das sessões de mediação, à formação e capacitação de mediadores qualificados e suficientes para suprir a demanda e também à remuneração destes profissionais. Neste contexto, este artigo reflete sobre problemas a serem enfrentados pelo Poder Judiciário

\footnotetext{
${ }^{1}$ Doutor e Mestre em Direito pela Instituição Toledo de Ensino. Professor de Direito Processual Civil, Direito Constitucional e Diretor do Curso de Direito da PUC - Campinas. Prof. Dr. da PUC Campinas e Advogado.

${ }^{2}$ Bacharel em Direito pela PUC - Campinas e Advogada.
} 
na implementação desse meio consensual e sugerir possiveis adequações que possam ser feitas no modelo brasileiro de mediação, com base na bem sucedida experiência argentina na implantação da mediação.

\section{PALAVRAS-CHAVE}

Sistema Multiportas; Acesso à Justiça; Mediação; novo Código de Processo Civil; Lei de Mediação.

\section{ABSTRACT}

In view of the provision expressed in the New Code of Civil Procedure and also in Law No. 13.140 / 15, mediation has become extremely important in Brazil as a means of resolving conflicts. However, this reality has generated practical questions regarding the infrastructure available to conduct the mediation sessions, the training and qualification of qualified mediators and sufficient to meet the demand and also the remuneration of these professionals. In this context, this article reflects on problems to be faced by the Judiciary in the implementation of this consensual environment and suggest possible adjustments that may be made in the Brazilian model of mediation, based on the successful Argentine experience in the implementation of mediation

\section{KEY-WORDS}

Multi-door system; Acess to Justice; Mediation; New Code of Civil Procedure; Mediation Law. 


\section{1) CONSIDERAÇÕES INICIAIS}

Os meios consensuais de solução de conflito, dentre os quais se encontra a mediação, vêm crescendo em importância, visto que a lei tem estimulado a utilização de meios autocompositivos, em detrimento da via estritamente judicial, com decisão de mérito prolatada pelo juízo. Tal preocupação se refletiu no Novo Código de Processo Civil (NCPC), sendo uma de suas propostas a superação da percepção atual de que existe o meio judicial e que todos os demais são meros meios alternativos, desenvolvendo-se, assim, uma noção de que existem outras formas possiveis para se resolver o litígio, igualmente importantes ao processo civil contemporâneo.

Além do NCPC, a Lei no 13.140/15, conhecida como Lei da Mediação, também veio contribuir para melhor regulamentar a mediação. Entretanto, as disposições trazidas por essas leis geram questionamentos de ordem prática, visto que a atual infraestrutura do Poder Judiciário ainda é insuficiente e inadequada para a nova realidade de crescente demanda pelo serviço de mediação, decorrente de sua obrigatoriedade como audiência inicial no procedimento comum.

Desse modo, o presente trabalho se presta a refletir sobre alguns problemas estruturais e profissionais a serem enfrentados pelo Poder Judiciário na implementação da mediação, tais como a criação dos centros judiciários de mediação, as parcerias com as câmaras privadas de mediação, a utilização da mediação online, os requisitos para se tornar mediador, e, por último, a remuneração desses profissionais. Além disso, são sugeridas possíveis adequações ao modelo brasileiro de mediação com base na experiência argentina.

2) O SURGIMENTO DA MEDIAÇÃO NO BRASIL E O SISTEMA DO TRIBUNAL MULTIPORTAS

Durante muito tempo tem predominado a resolução de conflitos por meios heterocompositivos, destacando-se a jurisdição como um dos 
meios mais procurados para solucionar litígios, o que tem gerado congestionamento de processos nos tribunais. Diante de tal fato, vários países começaram a buscar formas alternativas ao processo judicial, optando, em sua maioria, pelos meios autocompositivos como formas de "descongestionar” os órgãos jurisdicionais e garantir maior acesso à justiça, função esta que nunca foi apenas do Poder Judiciário, mas sim uma finalidade do Estado, o qual pode incentivar a solução dos conflitos no âmbito estatal ou fora dele, por meio de vários métodos privados. ${ }^{3}$

A edição da Resolução n ${ }^{\circ}$ 125/2010 do Conselho Nacional de Justiça $(\mathrm{CNJ})$ que dispõe sobre a "Política Judiciária Nacional de tratamento adequado dos conflitos de interesse no âmbito do Poder Judiciário", foi muito positiva para estimular os meios consensuais. Tal Resolução considerou a relevância de organizar e uniformizar os serviços dos meios consensuais e tentou estabelecer algumas diretrizes para auxiliar o Poder Judiciário na implantação de uma política mais efetiva de tratamento dos litígios. Assim, entende-se que esta Resolução consolidou no Brasil a implantação do que se tem chamado de Tribunal Multiportas, um sistema pelo qual o Estado:

coloca à disposição da sociedade alternativas variadas para se buscar a solução mais adequada de controvérsias, especialmente valorizados os mecanismos de pacificação (meios consensuais), e não mais restrita a oferta ao processo clássico de decisão imposta pela sentença judicial. Cada uma das opções (mediação, conciliação, orientação, a própria ação judicial contenciosa etc.), representa uma "porta", a ser utilizada de acordo com a conveniência do interessado, na perspectiva de se ter a maneira mais apropriada de administração e resolução do conflito. ${ }^{4}$

\footnotetext{
3 Por meio da heterocomposição o litígio é solucionado por um terceiro (magistrado, árbitro) com poderes para tanto e cuja decisão irá vincular as partes conflitantes, que ficarão submetidas a tal decisão, mesmo que esta não corresponda aos seus respectivos interesses. Na autocomposição um terceiro pode participar como facilitador da comunicação entre as partes, podendo até fazer propostas de solução, dependendo do caso concreto, porém, o resultado final depende apenas da vontade dos interessados. (CAHALI, Francisco José. Curso de Arbitragem: Mediação, Conciliação, Resolução CNJ 125/2010. 4ª Ed. Ver. Atual. E Ampl. - São Paulo: Editora Revista dos Tribunais, 2014. p. 41-42).

${ }^{4}$ CAHALI, Francisco José. Curso de Arbitragem: Mediação, Conciliação. Resolução CNJ 125/2010. São Paulo: Editora Revista dos Tribunais, 2014. p. 58.
} 
Esse sistema teve como base o modelo americano multidoor courtroom, adotado pelos EUA desde 1970, pelo qual o Poder Judiciário apenas em último caso deve ser o gestor do conflito.

Como consequência da Resolução $\mathrm{n}^{\circ}$ 125/2010 do CNJ, no ano de 2011, enquanto seguiam-se discussões sobre o projeto do NCPC, surgiu uma proposta de regulamentação da mediação com um detalhamento próprio, o que resultou na Lei da Mediação (Lei n $\left.{ }^{\circ} 13.140 / 2015\right)$ de modo que atualmente no Brasil tanto o NCPC quanto a Lei ${ }^{\circ}$ 13.140/15 estão disciplinando a mediação, sendo que a Lei de Mediação traz disposições sobre a mediação extrajudicial, câmaras privadas de mediação, bem como sobre a autocomposição envolvendo entes da Administração Pública.

\section{3) A MEDIAÇÃO NA ARGENTINA E UMA COMPARAÇÃO INICIAL COM O SISTEMA BRASILEIRO DE MEDIAÇÃO}

A Argentina se destacou ao colocar em seu ordenamento jurídico outras formas de resolução de disputas, além da tradicional tutela jurisdicional. Em 1991 iniciou-se a implementação de programas consensuais no país, com várias iniciativas para estimular a mediação ${ }^{5}$, destacandose a Lei $n^{\circ} 24.573$ de 1995 , que instituiu a mediação no país ${ }^{6}$, sendo posteriormente derrogada pela Lei $\mathrm{n}^{\circ} 26.589$ de 2010, atual lei que regulamenta o instituto na Argentina.

A Lei $n^{\circ} 26.589$ de 2010 instituiu a mediação obrigatória e prévia a todo processo judicial, na tentativa de se solucionar a demanda extrajudicialmente ${ }^{7}$, antes de se iniciar uma disputa judicial. Desse modo, no caso de a autocomposição restar infrutífera, a parte deve juntar a ata expedida pelo escritório responsável pela mediação em

\footnotetext{
${ }^{5}$ TARTUCE, Fernanda. Mediação nos Conflitos Civis. $2^{a}$ Ed., Ver. Atual. E Ampl. - Rio de janeiro: Forense; São Paulo: MÉTODO: 2015. Pág. 186.

${ }^{6}$ AMARAL, Márcia Terezinha Gomes. O Direito de Acesso à justiça e a Mediação. 2008. 154f. Dissertação (mestrado em Direito e Políticas Públicas) - Faculdade de Ciências Jurídicas e Ciências Sociais. Distrito Federal, Brasília.

${ }^{7}$ ARTÍ́CULO $1^{\circ}$, Ley 26.589.
} 
sua petição inicial para, então, ajuizar a ação judicial, pois a prova da tentativa de mediação é um requisito para que a demanda seja admitida no Judiciário ${ }^{8}$, sendo facultativa a mediação prévia nos casos de execução e despejos ${ }^{9}$.

Ainda pela Lei $\mathrm{n}^{\circ} 26.589$ de 2010, para ser mediador é necessário ser advogado com três anos de registro, provar ter feito o treinamento exigido pela regulamentação, ser aprovado em exame de aptidão, estar atualmente inscrito no Registro Nacional de Mediação e, por último, cumprir os demais requisitos eventualmente estabelecidos por outros regulamentos ${ }^{10}$. Cumprindo esses requisitos e uma vez inscrito como mediador, o profissional poderá ser designado por acordo entre as partes conflitantes, quando estas escolherem o mediador por convenção escrita; por sorteio; por proposta do requerente ao requerido, que irá selecionar um mediador de uma lista; ou ainda, durante a tramitação do processo, na qual o juiz poderá, apenas uma vez, submeter o caso ao procedimento de mediação, ficando o processo, nesse caso, suspenso por certo prazo ${ }^{11}$.

Realizada a audiência de mediação ${ }^{12}$ e havendo acordo entre as partes, o mediador, os interessados e os advogados irão assinar a ata da audiência e o procedimento consensual terminará. Na hipótese de não haver acordo, será lavrada ata com a assinatura de todos os envolvidos e o requerente poderá ajuizar a ação judicial para resolver a disputa. ${ }^{13}$

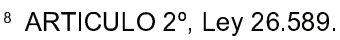

${ }^{9}$ ARTICULO $6^{\circ}$, Ley 26.589. O artigo $5^{\circ}$ da Lei $26.589 / 10$ traz alguns casos que não se submetem ao procedimento de mediação prévia obrigatória, tais como causas penais, ações envolvendo separação e divórcio, nulidade de casamento, filiação e pátrio poder e adoção, exceto as questões patrimoniais derivadas delas, declaração de incapacidade, casos em que o Estado ou alguma de suas entidades indiretas sejam parte, dentre outras hipóteses previstas no mencionado artigo.

10 ARTICULO 11, Ley 26.589.

11 ARTICULO 17, Ley 26.589.

12 Em regra, o prazo para ser realizada a mediação é de 60 dias corridos, contados da última notificação ao requerido (artículo 20, Ley 26.589)

13 ARTICULO 27, Ley 26.589.
} 
No que diz respeito aos honorários dos mediadores, a lei afirma que os mediadores receberão, por seu desempenho na mediação, honorário básico cujo montante e condições de pagamento serão fixadas por regulamentação do Poder Executivo. ${ }^{14}$

Já no modelo brasileiro a mediação não é um requisito para se ajuizar ação judicial, mas algo que deve, obrigatoriamente, ser tentado em audiência no início do procedimento, salvo se ambas as partes expressamente manifestem a vontade de não tentar a composição ou se não se tratar de caso passível de autocomposição ${ }^{15}$. Há também a possibilidade de mediação extrajudicial ${ }^{16}$.

Além disso, enquanto na Argentina se transferiu para o setor privado a responsabilidade de tentar mediar os interessados, no Brasil é função do Poder Judiciário fornecer uma estrutura que possibilite a mediação, não se excluindo a possibilidade de solução do conflito extrajudicialmente pelas Câmaras Privadas de Mediação ${ }^{17}$. Neste sentido o NCPC e a Lei de Mediação preveem que os tribunais deverão criar centros judiciários de solução consensual de conflitos, sendo estes responsáveis por realizar as sessões e audiências de mediação, bem como desenvolver programas voltados a auxiliar, orientar e estimular a autocomposição entre as

\section{${ }^{14}$ ARTICULO 35, Ley 26.589.}

${ }^{15}$ Art. 334, § 40, incisos I e II, NCPC. Caso apenas uma das partes ou ambas tenham interesse em realizar a audiência de mediação, o juiz irá designá-la e o procedimento, realizado por um mediador, deverá ser concluído em até 60 dias, ressaltando-se que é possível haver mais de uma sessão de mediação (art. 334 , caput e $2^{\circ}$ do NCPC; arts. 27 e 28 da Lei 13.140/15). No caso de apenas um interessado manifestar desinteresse na autocomposição, seja ele o requerente ou requerido, tal fato não impede que a audiência/sessão mediação seja designada. Se houver acordo na audiência de mediação, os autos são encaminhados ao magistrado, que irá arquivar o processo e, desde que requerido pelos mediandos, homologará o acordo por sentença, bem como o termo final da mediação e determinará o arquivamento do processo (art. 28, parágrafo único, Lei 13.140/15).

${ }^{16}$ Além da mediação judicial, caso as partes queiram tentar a autocomposição extrajudicialmente, basta que um dos interessados faça o convite para iniciar o procedimento de mediação extrajudicial, por qualquer meio de comunicação, devendo estipular o escopo proposto para a negociação, a data e o local da primeira reunião (art. 21, Lei 13.140/15). Também é possível a previsão contratual de mediação, também chamada de cláusula de mediação, a qual exige que algumas informações mínimas sobre o procedimento devem constar no contrato (art. 22 e parágrafos, Lei 13.140/15).

${ }^{17}$ A mediação extrajudicial é feita "sem o auxílio de componentes dos quadros jurisdicionais", enquanto a mediação será judicial "quando efetivada no curso de uma demanda já instaurada". (TARTUCE, Fernanda. Mediação nos Conflitos Civis. $2^{a}$ Ed., Ver. Atual. E Ampl. - Rio de janeiro: Forense; São Paulo: MÉTODO: 2015. p. 280-284.) 
partes ${ }^{18}$. Portanto, no Brasil, o Poder Judiciário assume a função de fornecer a infraestrutura para a mediação, ficando a cargo de cada tribunal a composição e organização dos referidos centros, desde que observada a Resolução 125/10 do CNJ.

Diferentemente da Argentina, no Brasil não se exige que o mediador seja Bacharel em Direito ou advogado, sendo possivel que um profissional de qualquer área seja mediador. Isso porque para ser mediador, principalmente judicial, é obrigatório ter certificado de participação em curso de capacitação de mediação ministrado por entidades devidamente credenciadas e ser graduado há pelo menos 2 anos em curso de ensino superior de instituição devidamente reconhecida ${ }^{19}$, salvo se o mediador for escolhido pelas partes para atuar no procedimento extrajudicial de mediação, hipótese em que qualquer pessoa capaz que tenha a confiança das partes e seja capacitada para fazer mediação pode ser mediador extrajudicial ${ }^{20}$. Quando cumprir esses requisitos de capacitação mínima determinados em lei, o profissional poderá requerer sua inscrição no Cadastro Nacional de Mediadores sob a responsabilidade do CNJ, podendo, a partir deste momento, atuar como mediador.

No Brasil a remuneração dos mediadores judiciais será custeada pelas partes, conforme tabela de honorários definida pelos tribunais ${ }^{21}$, enquanto que na mediação extrajudicial o estabelecimento dos honorários se dá pelo próprio mediador ou pela Câmara Privada à qual ele está vinculado,

\footnotetext{
${ }^{18}$ Art. 165, NCPC e art. 24, Lei 13.140/15.

${ }^{19}$ Art. 167 , caput e $\$ 1^{\circ}, \mathrm{NCPC}$ e art. 11 , Lei $13.140 / 15$.

${ }^{20}$ Art. $9^{\circ}$, Lei 13.140/15. Percebe-se que para atuar como mediador extrajudicial é preciso ter capacidade civil (requisito objetivo), confiança das partes (requisito subjetivo) e capacitação para mediar, porém este último requisito não está detalhadamente previsto na lei. Assim, é possível entender que o mediador extrajudicial não precisa, necessariamente, ter participado em curso de capacitação para mediação, bastando ele ter habilidades em mediar, enquanto o mediador judicial, mesmo quando escolhido pelas partes, precisa cumprir os requisitos de capacitação mínima previstos em lei.

${ }^{21}$ Art. 169, NCPC. Ressalta-se, entretanto, que a ressalva do art. 169 quanto à hipótese do $\S 6^{\circ}$ do art. 167 foi um equívoco, visto que este último dispositivo não traz nada a respeito da remuneração dos mediadores. Essa referência do art. 169 se vinculava à redação anterior do projeto de lei do CPC, a qual sofreu alteração durante seu processo legislativo. (SAMANTHA, Fernanda Medina Pantoja. A mediação no novo código de processo civil. Coordenação Diogo Assunção Rezende de Almeida. Rio de Janeiro: Forense, 2016. p. 165).
} 
cabendo às partes efetuar o pagamento, salvo nos casos em que for deferida gratuidade da mediação, tanto judicial como extrajudicial ${ }^{22}$.

\section{4) QUANTO À INFRAESTRUTURA PARA REALIZAR MEDIAÇÃO}

Diante da previsão de criação pelos tribunais de centros judiciários de solução consensual de controvérsias para realizar as sessões de mediação há necessidade de se conceber toda uma estrutura física para atender o aumento na demanda pela mediação, devido à obrigatoriedade prevista em lei. Além dos centros judiciais, a lei estabelece que os entes federativos também devem criar suas próprias câmaras de mediação para tentar solucionar conflitos no âmbito administrativo ${ }^{23}$.

Portanto, nota-se que há um desafio estrutural e gerencial a ser enfrentado pelo Poder Judiciário principalmente porque, em termos administrativos, a composição e a organização dos referidos centros ficará a cargo dos respectivos tribunais, observadas as disposições das normas do CNJ.

Tendo em vista que a audiência de mediação será realizada "em um espaço próprio, pensado e adequado para um momento informal e capaz de colocar as partes em uma situação confortável para a negociação e empoderamento" a implantação da mediação enseja ampliação na infraestrutura judiciária, além de "designar servidores, criar infraestrutura de abastecimento, de tecnologia da informação, organizar rotinas

\footnotetext{
${ }^{22}$ Art. $4^{\circ}, \S 2^{\circ}$, Lei $13.140 / 15$. Tendo em vista que essa possibilidade de gratuidade da mediação está nas disposições comuns, é possível concluir que até para a mediação extrajudicial a parte hipossuficiente pode requerer a Justiça Gratuita. Inclusive, o NCPC também prevê o dever dos Tribunais de determinar um percentual de audiências não remuneradas a serem suportadas pelas Câmaras Privadas de Mediação, com o fim de atender aos processos em que deferida gratuidade da justiça, como contrapartida de seu credenciamento (art. 168, $\S 2^{\circ}, \mathrm{NCPC}$ ). Dessa forma, uma Câmara Privada que deseje atuar em parceria com o Poder Judiciário precisa concordar em realizar determinado número de sessões de mediação gratuitamente para poder se credenciar e fornecer seu serviço de mediação.

${ }^{23} \mathrm{O}$ art. 32 da Lei 13.140/15 utiliza a expressão "poderão criar" enquanto a o art. 174 do NCPC (Lei 13.105/15) fala que os entes federativos "criarão câmaras de mediação e conciliação". Diante da controvérsia, considerando que o poder público é um dos maiores litigantes no Brasil, correto é se considerar a obrigatoriedade estabelecida no NCPC, visando desafogar o Poder Judiciário.
} 
e procedimentos". ${ }^{24}$ Os referidos centros judiciários, além de realizar as audiências e sessões de mediação, também será responsável pelo atendimento, orientação e estímulo aos meios consensuais.

A criação destes órgãos, dotados de certa autonomia em relação às unidades judiciais, é essencial para o funcionamento do modelo de processo civil proposto pelo CPC/2015, em que as tarefas de conciliação/mediação, preferencialmente, não serão afetas ao magistrado. ${ }^{25}$

Enquanto a estrutura judiciária estiver em processo de implementação para atender a crescente demanda de meios consensuais poderiam ser celebradas parcerias e convênios com as Câmaras Privadas de Mediação, visto que elas, por se focarem na prestação de serviços de mediação, possuem corpo de mediadores profissionais, que já fizeram cursos e dominam técnicas necessárias para auxiliar as partes na mediação. Para isso, tais câmaras deveriam se inscrever nos cadastros dos tribunais locais caso desejem atuar juntos deles.

Para se viabilizar a mediação, deve ser fomentada a utilização da mediação por meio eletrônico ${ }^{26}$, podendo-se contar, principalmente, com a estrutura das já mencionadas Câmaras de Mediação Privadas para oferecer, não apenas atendimento presencial, mas também por vídeo videoconferência. Dessa forma, por meio da mediação on line, seria possível às comarcas presentes em grandes centros, as quais, em geral, dispõem de melhor estrutura e mais recursos para seu funcionamento, a absorção de parte das demandas de mediação das comarcas menores, além de se ampliar a abrangência do alcance da mediação, na medida em que os meios eletrônicos possibilitam a diminuição da distância en-

${ }^{24}$ LESSA NETO, João Luiz. O Novo CPC Adotou o Modelo Multiportas!!! E Agora?!. Revista de Processo. vol. 244. ano 40. p. 427-441. São Paulo: Ed. RT, junho 2015. p. 433.

25 GAJARDONI, Fernando. Comentário ao art. 165. In: DELLORE, Luiz; DUARTE, Zulmar; ROQUE, André GAJARDONI, Fernando (coords.) Teoria geral do processo: Comentários ao CPC de 2015. Rio de Janeiro: Forense, 2015. Pág. 538.

${ }^{26}$ Art. 334, § 7o, NCPC 
tre as partes conflitantes, de modo que elas podem optar pela mediação, mesmo que estiverem em comarcas distantes, tornando desnecessário o deslocamento para comparecerem à sessão de mediação.

Além disso, quando se inicia a organização de um programa de resolução consensual de conflitos, além da estrutura física, também é preciso considerar outros aspectos como a capacitação e remuneração dos mediadores.

A primeira preocupação que se tem em relação aos mediadores refere-se a sua quantidade, visto que ainda não se tem um número de mediadores suficientes para suprir a crescente demanda pela mediação, devido, principalmente, ao fato de a tentativa de solução consensual do conflito (seja mediação ou conciliação) ser, em regra, obrigatória. Tal preocupação é relevante, na medida em que a oferta de cursos de mediação está crescendo lentamente e a maioria ainda oferece apenas ensino presencial, o que limita, em certa proporção, a quantidade de alunos a serem formados ${ }^{27}$. Esses fatores têm tornado o processo de formação de mediadores um tanto lento, sendo forçoso refletir sobre a necessidade de formação de mediadores por meio de ensino à distância, ainda que parte do curso seja presencial.

Outro ponto a se considerar é quanto aos critérios estabelecidos para o credenciamento de mediadores judiciais. Segundo o NCPC para um profissional requerer sua inscrição no cadastro de mediadores exige-se apenas o certificado de participação em um curso de mediação ${ }^{28}$, ficando possibilitado aos tribunais locais a realização de concurso público para selecionar seus quadros de mediadores judiciais. Já a Lei de Mediação determina que, além do referido certificado do curso, é preciso estar formado há pelo menos 2 anos em um curso superior, exigência que, apesar de garantir indivíduos com maior experiência profissional, não

${ }_{27}^{27}$ JÚNIOR, Asdrubal. Mediação Obrigatória no Brasil - Alguns desafios para o sucesso. Disponível em: http:// www.mo mentoarbitragem. com. br/arquivos/962. Acesso em: 14/10/16.

${ }^{28}$ Art. $167, \S 1^{\circ}$, NCPC. 
assegura, necessariamente, maior capacidade desses profissionais em atuar na mediação, atributo este que pode ser aprendido e aprimorado por meio de cursos de capacitação de mediadores e pela prática, posteriormente. ${ }^{29}$

Não obstante o valor inegável da experiência em qualquer modalidade de atuação profissional, cabe observar, contudo, que: a) nem todos os profissionais fazem sua própria experiência ser acompanhada de uma reflexão critica, que potencializaria em grande parte o aprendizado, mas muitas vezes terminam por atuar de forma automática e pouco criativa; b) é sem dúvida verdadeira a afirmação de que há diferentes caminhos para o desenvolvimento pessoal, mas este pode passar, sobretudo num estágio inicial, pelo conhecimento teórico e treinamentos, para em seguida se refletir na prática, quando a pessoa se deparar com problemas e necessidades reais. ${ }^{30}$

Assim, a participação em curso de capacitação de mediadores seria um dos melhores critérios a ser exigido para se requerer a inscrição no cadastro nacional, desde que tais cursos tenham um modelo de ensino pensado para formar profissionais para intermediar conflitos, contribuindo no entendimento da controvérsia pelos mediandos, com foco no restabelecimento do diálogo. Importante ainda que os cursos de capacitação exijam a realização de um certo número de horas de atuação em sessões de mediação reais ${ }^{31}$, equivalente a um estágio, supervisionado por mediadores já experientes.

Deve ser considerada também a remuneração dos mediadores, pois esse fator será relevante para estimular a criação e permanência de um

${ }^{29}$ SAMANTHA, Fernanda Medina Pantoja. A mediação no novo código de processo civil. Coordenação Diogo Assunção Rezende de Almeida. Rio de Janeiro: Forense, 2016. p. 195.

${ }^{30}$ SAMANTHA, Fernanda Medina Pantoja. A mediação no novo código de processo civil. Coordenação Diogo Assunção Rezende de Almeida. Rio de Janeiro: Forense, 2016. p. 195.

${ }^{31}$ A Resolução n 125 do CNJ prevê um módulo prático, chamado Estágio Supervisionado, no qual o aluno atende casos reais de mediação, sendo uma etapa imprescindível para a obtenção do certificado de conclusão do curso de capacitação de mediadores (que habilita o mediador a atuar perante o Poder Judiciário). Disponível em: http://www.cnj.jus.br/busca-atos-adm?documento=2579. Acesso em: 12/10/16. 
bom quadro de mediadores, devendo tal valor, contudo, ser proporcional aos valores arcados pelas partes no tocante às custas e às demais despesas processuais. Caso haja necessidade, deverá ser concedido o já mencionado benefício da gratuidade da mediação, para não tornar este instrumento inacessivel às camadas mais carente da população.

\section{5) POSSÍVEIS CONTRIBUIÇÕES DO MODELO ARGENTINO NA IMPLEMENTAÇÃO DA MEDIAÇÃO NO BRASIL}

Apontadas algumas questões (estrutural e profissional) que trazem certa preocupação, pelo menos em um primeiro momento, é interessante destacar possíveis contribuições do modelo argentino de mediação na implementação do instituto consensual no Brasil.

Em um país de dimensões continentais, grande população e quantidade imensa de processos, não basta agilizar o processo judicial (...). Há que se implementar medidas mais profundas de redução da quantidade de causas. Por isso, tem-se buscado, outrossim, popularizar meios alternativos de solução de conflitos, inspirados muitas vezes em experiências bemsucedidas no exterior, visando desafogar o Poder Judiciário. ${ }^{32}$

A primeira característica do modelo argentino que poderia ser utilizada pelo Brasil seria o enfoque na mediação privada. Na Argentina a mediação é exclusivamente privada, de modo que, além de apenas ser permitido aos advogados formados há pelo menos três anos atuar como mediadores, a tentativa de mediação é feita nos próprios escritórios de advocacia, enquanto no sistema brasileiro, como demonstrado, o encargo de realizar as sessões de mediação ainda está muito concentrado no Poder Judiciário ${ }^{33}$. Assim,

\footnotetext{
32 BASÍLIO, Ana Tereza Palhares. Projeto de Lei da Mediação Obrigatória e a busca da pacificação social. Revista de Arbitragem e Mediação. Vol. 4, n. 13, p. 38-57, abr./jun, 2007. São Paulo: Ed. RT, p. 38.

${ }^{33}$ Mesmo que a reunião de mediação seja feita por um centro judiciário ou por uma câmara designada para atuar no caso, a mediação será considerada judicial na hipótese de o autor ter apresentado petição inicial ao juízo, pois, nesse caso, caberá ao magistrado analisar se estão presentes os requisitos inicial e determinar a citação da parte contrária para comparecer à audiência de mediação ou conciliação. Assim, as partes podem escolher o mediador, de comum acordo, porém, se elas não acordarem sobre essa escolha, o próprio juízo irá designar um de seus mediadores judiciais ou uma câmara privada de mediação credenciada para atuar no caso. Em ambas as possibilidades a mediação será considerada judicial pois está atrelada ao Poder Judiciário.
} 
percebe-se que no modelo argentino presa-se pela mediação prévia, ou seja, antes mesmo de se ajuizar a ação judicial os interessados devem tentar a autocomposição, o que, sem dúvida, diminui a quantidade de processos judiciais, visto que se a mediação for exitosa, a parte autora nem sequer apresentará petição ao juízo, deixando de haver provocação do Poder Judiciário.

No Brasil existe possibilidade da mediação privada (extrajudicial), na qual as partes interessadas procuram, por si só, um escritório ou câmara de mediação que auxilie na autocomposição, sem a necessidade de acionar o Poder Judiciário. Porém trata-se de uma faculdade das partes, o que, na maioria absoluta dos casos, acarreta no ingresso pela via jurisdicional obrigando o Poder Judiciário a criar enorme infraestrutura para atender a demanda pelos meios consensuais de solução de conflito.

Nesse ponto o modelo argentino, ao deixar a iniciativa privada responsável pela mediação, possibilitou que cerca de 30\% das demandas nem sequer vão para o Judiciário, sendo o conflito resolvido já na mediação prévia (pré-processual) ${ }^{34}$. Assim, como bem aponta o advogado e professor argentino Dr. Manuel Osvaldo Cobas, solucionar o conflito pela mediação pré-judicialmente, sem ir a juízo, é algo que traz celeridade para resolver a controvérsia e também beneficios econômicos, tanto para as partes quanto para o próprio advogado mediador, pois aqueles terão a possibilidade de solucionar seu conflito de maneira mais célere e menos custosa ${ }^{35}$.

Nota-se que o Brasil não aproveitou esta vantagem do modelo argentino, pois deixou às partes apenas a faculdade de tentar a mediação pré-processual. Talvez poderia ser adotado no Brasil a mesma obrigatoriedade de mediação pré-processual, deixando para o Poder Judiciário exercer a mediação apenas nos casos de direitos indisponíveis.

Há no sistema argentino apenas um cadastro nacional no qual os

\footnotetext{
${ }^{34}$ JÚNIOR, Asdrubal. Mediação Obrigatória na Argentina e no Brasil. Disponível em: http://www.momen toarbitragem.com. br/arquivos/1045. Acesso em: 15/10/16.

${ }^{35}$ JÚNIOR, Asdrubal. A Experiência Argentina em Mediação. Disponível em: http://www.momentoarbitragem. com.br/arquivos/931. Acesso em: 15/10/16.
} 
advogados precisam se inscrever para exercerem a função de mediadores, enquanto no modelo brasileiro o NCPC determinou a criação de dois tipos de cadastros, sendo um deles nacional, mantido pelo CNJ e outro relacionado a cada um dos Tribunais. Tal pluralidade de cadastros parece ser desnecessária, de modo que apenas a existência do cadastro nacional já dispensaria a necessidade de se criar cadastros locais para os tribunais.

Para resolver isso, nada impede, que

(...) do cadastro nacional, conste informação em relação a qual ou quais tribunais e comarcas pretende o mediador ou conciliador atuar. A partir de tais dados, que deverão ser disponibilizados aos tribunais locais, estes poderão identificar a quais mediadores e conciliadores poderão ser distribuídas as causas em tramitação naquele órgão. ${ }^{36}$

Além disso, a manutenção de tais cadastros setoriais demanda "alocação de equipamentos eletrônicos, de pessoal e, portanto, de recursos, o que, ao nosso ver, não só não se justifica como ainda gera inconvenientes", além de haver risco de exclusão de um mediador de um cadastro local e sua manutenção no cadastro nacional. ${ }^{37}$

\section{6) CONSIDERAÇÕES FINAIS}

Há de se reconhecer a importância do NCPC e da Lei de Mediação ao estabelecerem o sistema multiportas no Brasil, pois há necessidade de se criar a cultura de solução de conflitos por diversas formas, devendo os sujeitos serem "atores" na solução do conflito, reconhecendo outras figuras, para além do juiz, capazes de contribuir na pacificação. Entretanto, pecou o legislador brasileiro ao deixar a mediação extrajudicial apenas

${ }^{36}$ MAIA, Andrea; HILL. Flávia Pereira. A mediação no novo código de processo civil. Coordenação Diogo Assunção Rezende de Almeida. Rio de Janeiro: Forense, 2016. p. 158.

${ }^{37}$ MAIA, Andrea; HILL. Flávia Pereira. A mediação no novo código de processo civil. Coordenação Diogo Assunção Rezende de Almeida. Rio de Janeiro: Forense, 2016. p. 158 
como uma faculdade das partes, insistindo na cultura paternalista de invocação da tutela jurisdicional. Desta forma, haverá o início de mais um processo judicial, com a movimentação de toda a máquina judiciária para a solução deste conflito. Mesmo que o conflito seja solucionado na audiência inicial de mediação, haverá necessidade de designação da audiência, citação do réu, intimação da parte autora, designação de mediador e posterior homologação da mediação realizada, caso frutífera. Sem contar a necessidade de aparelhamento do Poder Judiciário para atender a crescente demanda do sistema multiportas de solução de conflito, seja no tocante à infraestrutura, seja quanto à criação e manutenção de bons quadros de mediadores.

Por todo o exposto, há necessidade de adequações para o sistema brasileiro de mediação ser implementado de maneira mais eficaz, para que tanto operadores do Direito, como a sociedade e o Estado passem a enxergar a mediação como um meio pleno de resolver seus conflitos de interesse, sem a necessidade de recorrer à via adjudicatória, estimulando-se a mediação que tem o potencial de resolver controvérsias de forma mais rápida, adequada e menos custosa, tanto para as partes, como para o Estado.

De todo modo, talvez seja necessário um tempo de aplicação dos dispositivos do NCPC e da Lei de Mediação para que seja criada a cultura da possibilidade de solução extrajudicial do conflito, para que, em um segundo momento, seja incorporada a característica do modelo argentino da obrigatoriedade da realização da mediação extrajudicial como condição para a propositura da ação judicial. 


\section{REFERÊNCIAS}

AMARAL, Márcia Terezinha Gomes. O Direito de Acesso à justiça e a Mediação. 2008. 154f. Dissertação (mestrado em Direito e Políticas Públicas) - Faculdade de Ciências Jurídicas e Ciências Sociais. Distrito Federal, Brasília.

BASÍLIO, Ana Tereza Palhares. Projeto de Lei da Mediação Obrigatória e a busca da pacificação social. Revista de Arbitragem e Mediação. Vol. 4, n. 13, p. 38-57, abr./jun, 2007. São Paulo: Ed. RT.

BRASIL. Lei 13.105/2015, de 16 de março de 2015. Código de Processo Civil. Diário Oficial da República Federativa do Brasil, Brasília, 13 mar. 2015. Disponivel em: < http://www.planalto.gov.br/ccivil_03/_ato20152018/2015/lei/113105.htm>. Acesso em: 16 de maio de 2016.

BRASIL. Lei 13.140/2015, de 26 de junho de 2015. Dispõe sobre a mediação entre particulares como meio de solução de controvérsias e sobre a autocomposição de conflitos no âmbito da administração pública; altera a Lei $\mathrm{n}^{\circ} 9.469$, de 10 de julho de 1997, e o Decreto $\mathrm{n}^{\circ} 70.235$, de 6 de março de 1972 ; e revoga o $\S 2^{\circ}$ do art. $6^{\circ}$ da Lei $n^{\circ} 9.469$, de 10 de julho de 1997. Diário Oficial da República Federativa do Brasil, Brasília, 29 jun. 2015. Disponivel em: < http://www.planalto.gov.br/ccivil_03/_Ato2015-2018/2015/ Lei/L13140.htm>. Acesso em: 16 de maio de 2016.

BRASIL. Conselho Nacional de Justiça. Resolução n 125 de 29/11/2010. Dispõe sobre a Política Judiciária Nacional de tratamento adequado dos conflitos de interesses no âmbito do Poder Judiciário e dá outras providências. Disponivel em: http://www.cnj.jus.br/busca-atos-adm?documento $=2579$. Acesso em: 04/07/2016.

BRASIL. Senado Federal. Anteprojeto do Novo Código de Processo Civil. Comissão de Juristas instituída pelo Ato do Presidente do Senado Federal n ${ }^{\circ}$ 379, de 2009, destinada a elaborar Anteprojeto de Novo Código de Processo Civil. Disponivel em: https://www.senado.gov.br/senado/novocpc/pdf/Anteprojeto.pdf. Acesso em: 16 de maio de 2016. 
CAHALI, Francisco José. Curso de Arbitragem: Mediação, Conciliação, Resolução CNJ 125/2010. São Paulo: Editora Revista dos Tribunais, 2014.

CAPPELLETTI, Mauro; BRYANT, Garth. Acesso à Justiça. Tradução: Ellen Gracie Northfleet. Porto Alegre: Fabris, 1988. Reimpresso: 2002.

DUPUIS, Juan Carlos G. La Reforma Judicial em Argentina: Justicia Inmediata. Menor Cuantia Y Sistemas Alternativos de Resolución de Conflictos. A Cuatro Años de la Mediación. Disponivel em: http://www.foresjusticia. org.ar/eventos/ mendoza/trabajos/jcarlosdupuis.ht. Acesso em: 16 de outubro de 16 .

GAJARDONI, Fernando. Comentário ao art. 165. In: DELLORE, Luiz; DUARTE, Zulmar; ROQUE, André; GAJARDONI, Fernando (coords.) Teoria geral do processo: Comentários Ao CPC de 2015. Rio de Janeiro: Forense, 2015.

GONÇALVES, Marcelo Barbi. Meios Alternativos de Solução de Controvérsias - Verdades, ilusões e descaminhos no Novo Código de Processo Civil. Revista de Processo. vol. 242. Ano 40. P. 597-629. São Paulo: Ed. RT, abr. 2015.

JÚNIOR, Asdrubal. A Experiência Argentina em Mediação. Disponivel em:<www.momentoarbitragem.com.br>. Acesso em: 15/10/16.

JÚNIOR, Asdrubal. Mediação Judicial e Extrajudicial Novo CPC - Lei de Mediação. In: FÓRUM DE DIREITO DAS IES CATÓLICAS, II., 2015, Canoas - RS. Disponivel em: <http://anec.org.br/forumdireito/wpcontent/ uploads/sites/5/2014/ 09/palestraAsdrubal.pdf> . Acesso em: 16 de maio de 2016.

Mediação Judicial e Extrajudicial Novo CPC - Lei de Mediação. In: FÓRUM DE DIREITO DAS IES CATÓLICAS, II., 2015, Canoas RS. Disponível em: <http://anec.org.br/forumdireito/wpcontent/uploads/ sites/5/2014/ 09/palestraAsdrubal.pdf> . Acesso em: 16/05/2016.

Mediação Obrigatória na Argentina e no Brasil. Disponível em: <www.momentoarbitragem.com.br>. Acesso em: 15/10/16. 
Mediação obrigatória no Brasil - Quais os desafios para o seu sucesso. Disponivel em: http://www.momentoarbitragem.com.br/arquivos/962. Acesso em: 11/10/16.

LESSA NETO, João Luiz. O Novo CPC Adotou o Modelo Multiportas!!! E Agora?! Revista de Processo. vol. 244. ano 40. p. 427-441. São Paulo: Ed. RT, junho 2015 .

LEVY, Fernanda; MANDELBAUM, Helena; BAYER, Sandra; ALMEIDA, Tania; NETO, Adolfo Braga; LORENCINI, Marco. Resolução n. 125 do Conselho Nacional de Justiça: Leitura comentada. Disponível em: http:/ /www. mediare.com.br/2016/03/07/resolucao-n-125-do-conselho-nacional-dejustica-leitura-comentada/. Acesso em: 27/09/2016.

MAIA, Andrea; HILL. Flávia Pereira. A mediação no novo código de processo civil. Coordenação Diogo Assunção Rezende de Almeida. Rio de Janeiro: Forense, 2016.

MEDINA, Eduardo Borges de Matos. Meios Alternativos de Solução de Conflitos: o cidadão na administração da justiça. Porto Alegre: Sergio Antonio Fabris Editor, 2004.

PAUMGARTTEN, Michele. Os Desafios para a Integração das Práticas Conciliatórias ao Novo Processo Civil. Revista de Processo. vol. 247. ano 40. p. 475-503. São Paulo: Ed. RT, setembro 2015.

PEREZ, Adriana Hahn. A Nova Lei Alemã de Mediação. Revista de Processo. vol. 243. ano 40. p. 555-581. São Paulo:Ed. RT, maio 2015.

RISKIN, Leonard L. Mediator Orientations, Strategies and Techniques, In: MENKEL-MEADOW, Carrie J.; LOVE, Lela Porter; Schneider, Andrea Kupfer; STERNLIGHT, Jean R. Dispute Resolution: Beyond the Adversarial Model, Nova York: Aspen, 2005. 
SOUZA, Luciane Moessa de. Mediação: Breve Análise da Proposta Brasileira e das Experiências Argentina e Colombiana na Normatização deste método de Solução de Conflitos. Disponível em: http://www.ambito-juridico.com.br/site/index.php?n_link=revista_artigos_leitura \&artigo_id=1426. Acesso em: 04/07/2016.

TARTUCE, Fernanda. Mediação nos Conflitos Civis. $2^{\text {a }}$ Ed., Ver. Atual. E Ampl. - Rio de janeiro: Forense; São Paulo: MÉTODO: 2015.

WATANABE, Kazuo. Cultura da sentença e cultura da pacificação. In: MORAES, Maurício Zanoide; YARSHELL, Flávio Luiz (coords.) Estudos em homenagem à professora Ada Pellegrini Grinover. São Paulo: DPJ, 2005. 